\title{
Identification Of Personality Traits Of The Profile Organizational Psychologist In Training, Based On Zülliger Test
}

\author{
Pilar Carolina Contreras-Milián
}

Master's student in organizational psychology.

CONACYT scholarship holder

Manuel González-Pérez

$\mathrm{PhD}$. Full-time researcher. National Research System Level 1 (SNI-1)

\section{Ana María Alejandra Herrera-Espinosa}

PhD. Full-time researcher. Project Director.

Universidad Popular Autónoma del Estado de Puebla,

Centro Interdisciplinario de Posgrados, Investigación y Consultoría

doi: 10.19044/esj.2016.v12n5p328 URL:http://dx.doi.org/10.19044/esj.2016.v12n5p328

\begin{abstract}
Researchers and professionals use psychometric psychology test as one of the main tools for measuring and personality assessment of candidates for a position in an organization. However, projective tests are being used tiny due to the lack of specialists in the field and represent the cost to companies. This study focuses Zulliger the test (TZ). The TZ is a projective psychometric test, which was tested through rigorous research as a valid and reliable. The aim of this study was to identify the personality traits of the organizational psychologist in training. This quantitative study is exploratory and descriptive cutting range. It was conducted in the period from February to July 2015. Through characteristic profile results of organizational psychologists in training at a private university was built.
\end{abstract}

Keywords: Personality traits, Organizational Psychologist Profile, Zülliger test

\section{Introduction}

\section{Overview}

Human Resource Management (HRM) has as one of its main tasks the organizations providing the necessary elements. Organizational Psychology (OP) has the task of selecting, training, support and the process of conducting life and career. OP has the knowledge required to perform the evaluation process and detection of talent in people. 
Psychologists and scientists developed different measurement tools through the years. The Psychometric Test (PT) or measuring tools facilitate and complement the process of detection and diagnosis of talent in people. The PT allows collecting data on personality traits of a subject. Researchers rated the PTs according to different methodologies, diversity and presentation material for its application (González, 2007). In general, the science of psychometrics has a technological and methodological arsenal according to the classification of the PT.

Currently, organizations and professionals who evaluate staff have digitized instruments. The instruments allow digitized times that are an efficient application of psychometric tests. The main disadvantage is that only digitized instruments have a quantitative basis. The rating of digitized instruments is performed automatically through a system, and the results provide digitized instruments be standardized and have a rigorous analysis. The instruments do not evaluate digitized projective characteristics.

For all this we must ask, what is happening with the use of projective tests in the workplace? Organizational psychologists evaluators know the existence of the Zülliger Test (ZT)? How is being the formation of organizational psychologists? Does such training include knowledge of projective assessment?

In the early 20's, it began to locate employees based on better use of their resources to achieve greater productivity. To identify this use of resources was necessary evaluations with a projective personality test to look for increased productivity. Hans Zülliger is one of their representatives to the creation of projective test. (Hidalgo and Peker, quoted by Nuñez Lara Guzman, Gürter and Diaz, 2010).

The ZT is considered as a test for their origin projective structural classification. Hans Zülliger developed and published his test in an original version in 1954. Zülliger made his test seeking to provide a contribution to the projective assessment in the workplace. The purpose of Zülliger was in the forecast performance of the person in a particular position (Richino, 2000). Hans Zülliger took into account that the application time was short (Ceballos and Solis, 2004).

On the other hand, the ZT has its roots and methodological bases in the Rorschach Test (TR). The TR is considered as one of the psychodiagnostic tests with more developments and studies in different parts of the world. The theoretical basis of the ZT has shown the value when used in the diagnostic evaluation of personality in the organizational area.

\section{Description of $\mathrm{TZ}$}

The ZT consists of three sheets with stains. The first sheet has a spot with shades of gray, black and white. The second sheet is only displayed in colors. 
The third film has ample areas in black and gray, red in a central area and two sides. For the implementation of the ZT, the assessed subject should structure the material of the three films, answering the question "What could this be?" When each sheet is displayed. The application data are encoded according to the Exner Comprehensive System (ECS). The ZT has a quantitative basis, and ECS provides theoretical support (Rivera and Cubas, 2010).

\section{Using the $\mathrm{ZT}$}

Currently, the ZT is widely used in South America. In Chile it has been used as entrance exam for students in the career of Psychology (Gallardo, Alvarez and Rojas, 2003).

Angelica Zdunic, originally from Argentina, is one of its principal representatives. She has made many studies on the ZT. The Zdunic studies have relied on the reasoning test. Studies determination of descriptive statistics has been applied in different age ranges, being valid and reliable (Redondo, Oggero, and Moritán, 2005 and Zdunic, Agemián, Kimmelman, Magazzu, (2011). The use of ZT in Mexico has remained out of reach of organizational psychologists and staff dedicated to performing evaluation of human talent. Trainees in the area of organizational psychology do not have scope to the ZT.

\section{Methodology}

The object of study of this research work corresponds to the analysis and identification of the personality characteristics of organizational psychologists in training. A quantitative methodology is addressed through ZT.

The study is exploratory because it examines an issue that has not been researched in Mexico. Also, research has a descriptive and transactional scope.

The purpose of the research is to search, specify and describe the personality characteristics in building a profile. These features are achieved through the collection of data at one time and one time (Hernandez-Sampieri, Fernandez, and Baptista, 2014).

A sample of 35 students studying the singles fourth-semester degree in organizational psychology of a private higher education institution was taken. Of these students, 22 were women and 13 men with an average age of 20.5 years. The sample was not probabilistic because it was chosen considering certain characteristics of the investigation. We sought to make a contribution to the training of organizational psychologists according to Johnson, Hernandez-Sampieri, et al. and Battaglia (cited by HernandezSampieri et al., 2014). 


\section{Results and discussion}

The results provided by the ZT are classified based on seven categories. The classification categories provide insight profile. The seven categories are response styles, styles reaction, operations cognitive, affective operations, motivations, concerns about the world and interpersonal perception.

To obtain the results frequency tables were performed. Frequency tables allow the identification of the characteristics depersonalized outstanding. The seven categories show a profile of the organizational psychologist at a private university:

Figure 1 displays the results of the categorization of response styles. $\mathrm{R}$ score showed that $100 \%$ of the population are active and productive. Weary they to their tasks only receive a general indication of the research. The quality of the results is not always good because they experience insecurity.

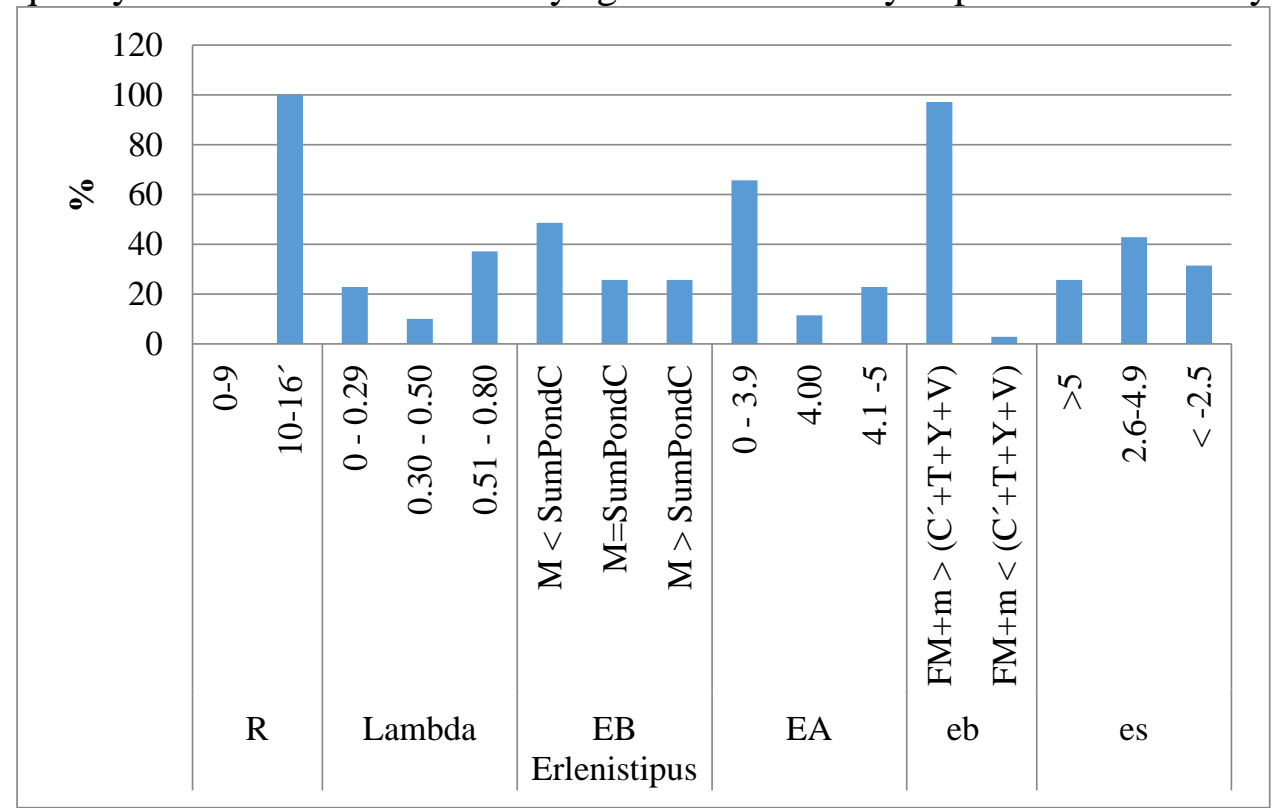

Figure 1. Response Styles

Regarding the management of emotions identified by lambda, the results establish that $37.14 \%$ of the population remains outside their emotions when it comes to making decisions. The $22.86 \%$ are people who come to data exceeded due to the difficulty of understanding them. They have trouble organizing their thoughts and deal with problems they face. Its effectiveness is constantly affected. $40 \%$ of the sample is within the average.

In solving problems and how to react to live situations identified by Erlenistipus, the $48.57 \%$ subjects using trial and error. They are much more emotional and include their affections to conduct assessments. They prefer to perform tasks involving interaction with others. They are considered 
perennials and entrepreneurs. They are people who like change and action. They prefer to resolve issues quickly. They prefer one to one communication in person. They learn through experimentation and sharing with others. By contrast, the $25.71 \%$ are people who are more introversive available. They keep their emotions aside and use their thinking to solve problems. They feel more comfortable in situations where there is need to interact with others. The $25.71 \%$ are people who take much time to think things through and make decisions. They have a little predictable performance.

Regarding the availability of resources to address the situations that arise in everyday life, identified by the EA decisive. The $65.71 \%$ lack sufficient resources to initiate deliberate behavior. Difficulty making decisions and implementing them. $11.43 \%$ is within the average. The $22.86 \%$ has the resources to handle any situation that comes the way.

Regarding the control of stimuli, ideas and emotions that are even present unexpectedly in person. $97.14 \%$ live with the internal tensions of the past constantly generate them suffering and pain. They have impulsive behaviors. 2.86\% have emotional burdens caused by situations currently living. Therefore, it was found that $31.43 \%$ of the population is in poor condition to face pressure, and $68.57 \%$ on the faces of little assertively. Information provided by the eb and determinants.

Figure 2 shows the results obtained in the categorization of styles reaction XA\% to understanding the way we see and understand the information that people perceive the context in which they operate as well as their degree of adaptation. The $85.71 \%$ of the population are people with an adequate perception of reality and use their discretion with equanimity. The $14.28 \%$ do not have that feature.

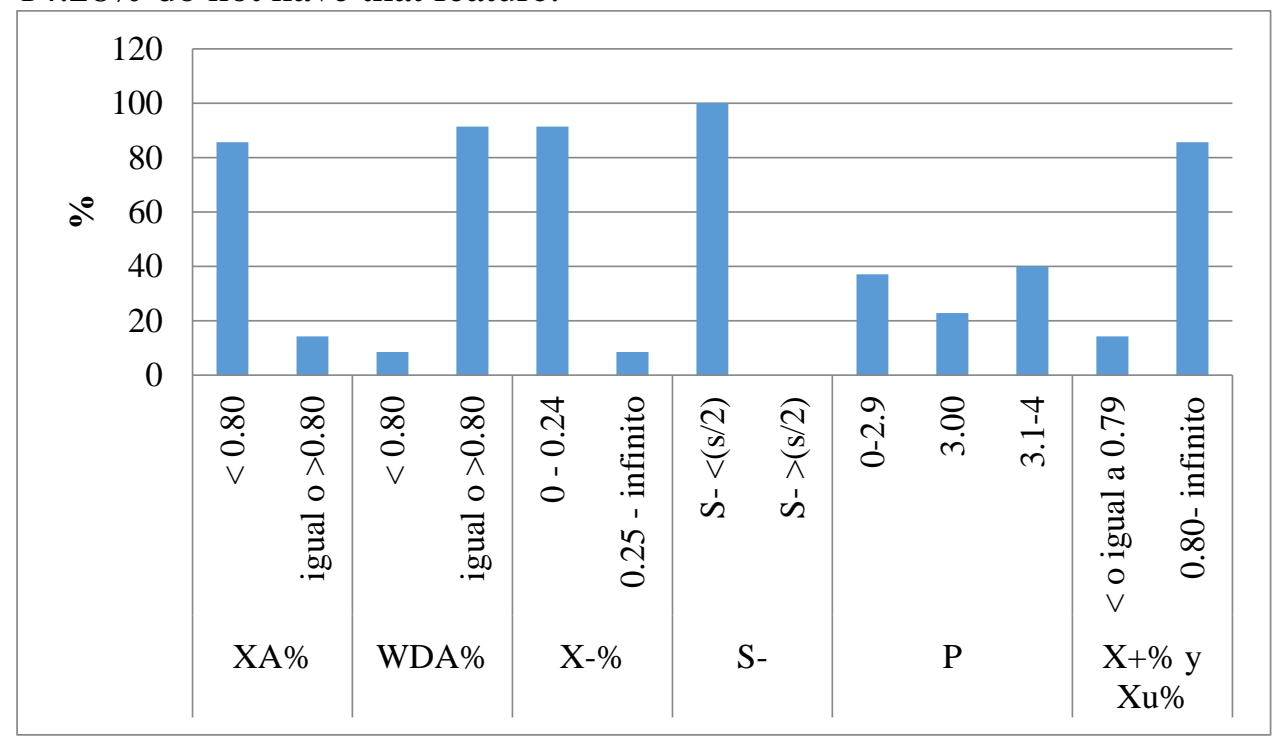

Figure 2. Reactions Styles 
Regarding the degree of adaptation to the conventional, WDA\% and X\% yielded data that $91.42 \%$ of the sample are people who adapt easily, so they can easily stick to a routine. However, the $8.57 \%$ lacks such a facility, so exist people who show signs of significant mismatch. Despite having adjustment problems are not oppositional people as it was found that $0 \%$ of the population has this feature of behavior. This information is thrown by the determining S-.

On adaptation to standards, $\mathrm{P}$ results showed that $40 \%$ of individuals undergoing excessively established social norms, the $22.86 \%$ is within the average adaptation and that $37.14 \%$ had difficulties serious to adapt, so they are more inclined to work where it is most privileged creative ability. This information is confirmed by the results of $\mathrm{X}+\%$ and $\mathrm{Xu} \%$.

Furthermore, Figure 3 shows the results of the categorization of cognitive operations, where it is expected that the determining p, MOR, M-, Level 2 and MQsin do not obtain a score, so they were not significant for interpretation. Among the determinants of which a significant score was obtained, it was found that $91.42 \%$ of the sample scored with Ma, which refers to are people who maintain an active role in what they do and do not necessarily require someone to He is constantly leading in their doing. They have the intelligence to address the problems they encounter, and can lead others. However, the $8.57 \%$ punctuated with Mp; it has trouble because they are people who have difficulty making decisions.

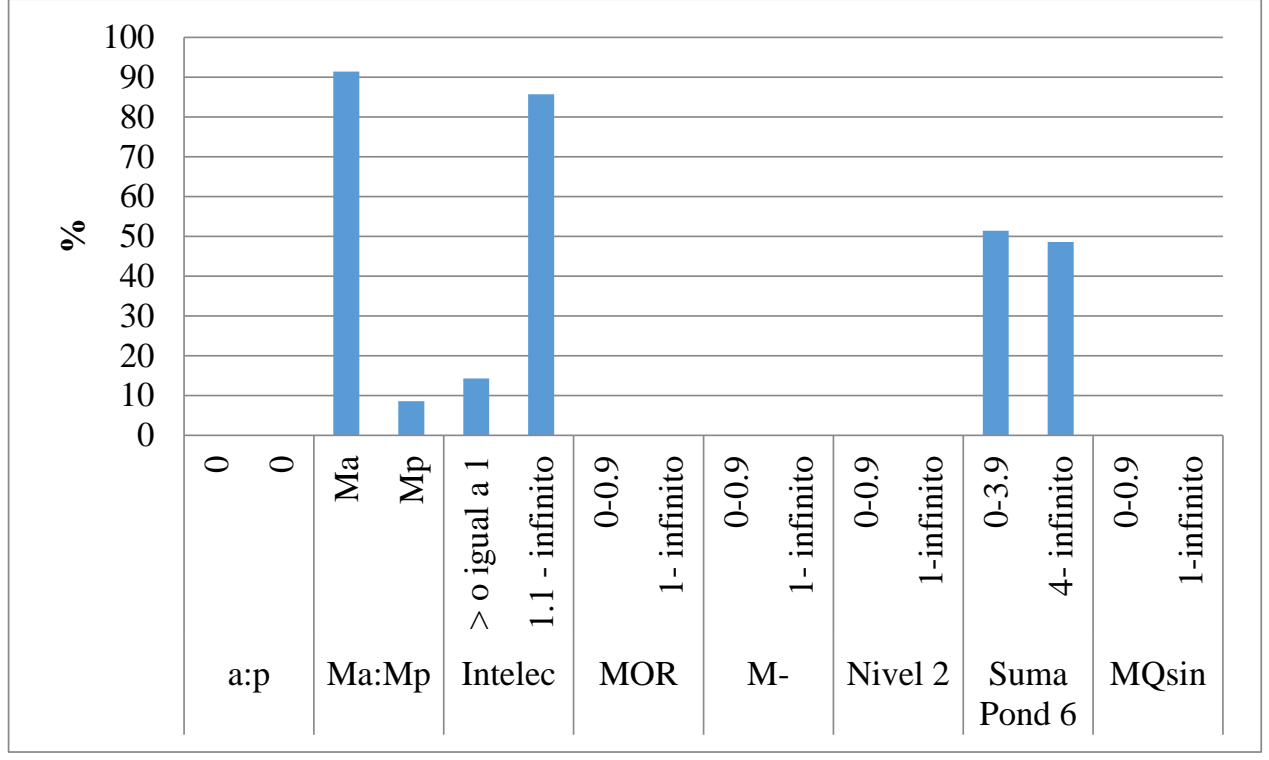

Figure 3. Cognitive operations

Moreover, it was found that $14.28 \%$ are people who intellectualize to situations they face, this in response to the difficulty of coping with the 
tension. The $85.71 \%$ is within the average. The results of the weighted sum of 6 are not found to be significant according to the analysis in conjunction with other determinants.

Figure 4 shows the results of the categorization of emotional operations, where according to FC: $\mathrm{CF}+\mathrm{C}$, it was found that $51 \%$ of the population control bit emotional shock, so their thoughts, decisions, and behaviors are dyed too much for her affections. This talk, that are strong and able to appear as people. However, the $48.57 \%$ of the population has good control of his emotions.

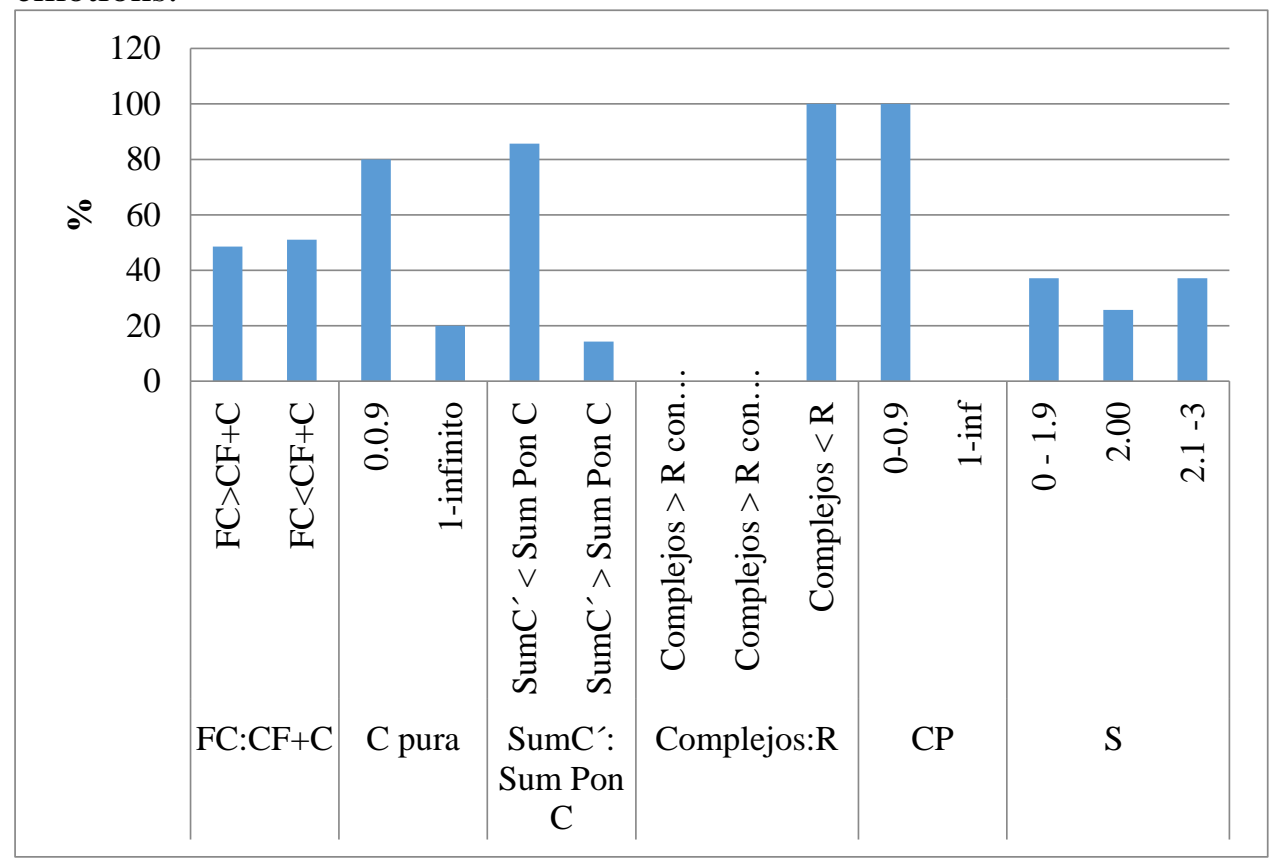

Figure 4. Affective operations

Moreover, pure C identifies that $20 \%$ are people who enjoy engaging in breakneck situations or hasty in which not required to make use of reflection and analysis; $80 \%$ of the population has no such feature as such.

Complex: R, it shows that in general, $100 \%$ of the sample are people looking excessive simplify the information they receive from their context.

About the expression of emotions, as measured by the determinant SumC': SumPonC, it was found that the $14.28 \%$ have severe difficulties in expressing what they feel, however, $85.71 \%$ is within expectations. Scores of $\mathrm{S}$ are not found to be significant due to their analysis related to other determinants.

The results of the categorization of motivations are shown in Figure 5. The determinant W: D: Dd shows that $74.29 \%$ of the population is very concerned about the details and accuracy in the preparation of their work. 
This feature is present in its need for greater confidence and not make mistakes. However, this impacts negatively on their performance as it directly affects its practical effectiveness. Only $2.86 \%$ is out of this preoccupation, and $22.86 \%$ is within the average.

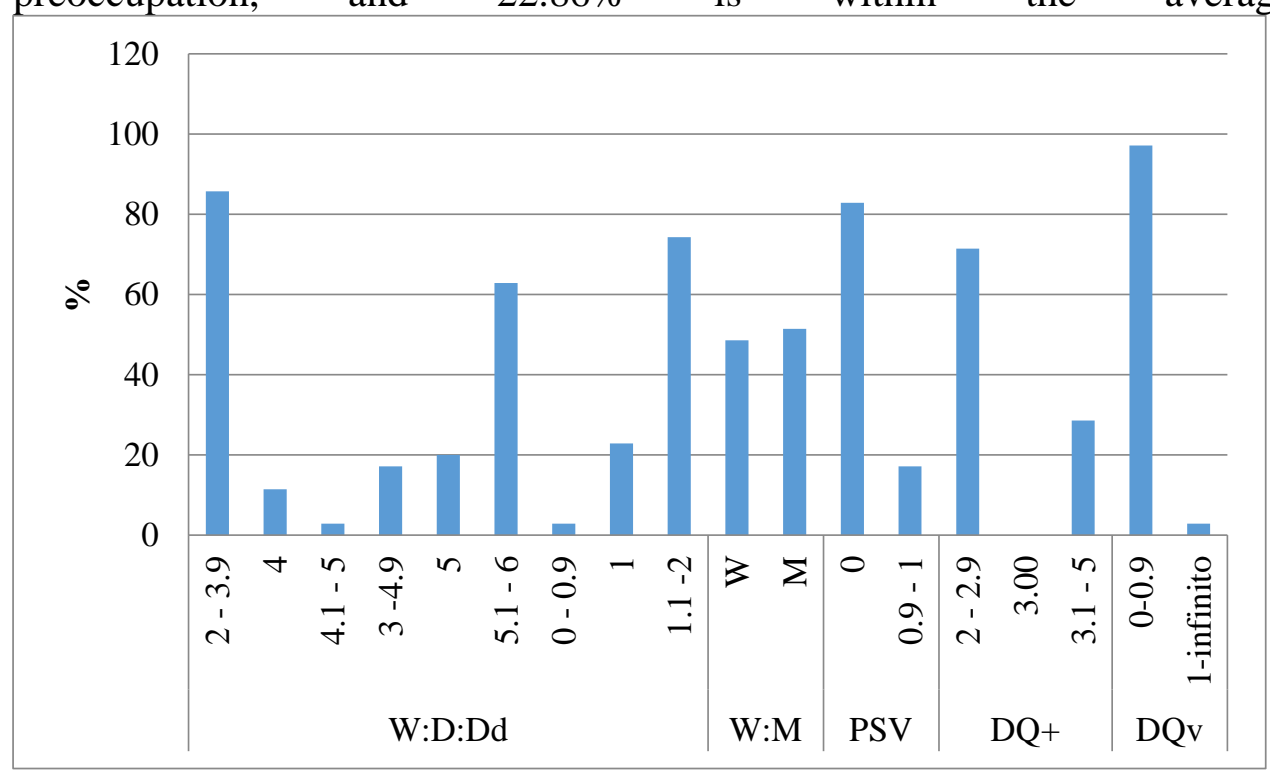

Figure 5. Motivations

Regarding the establishment of goals and objectives identified by the determinant $\mathrm{W}$ : $\mathrm{D}$, it was found that the $51.42 \%$ of the sample, goals that are beyond their real possibilities pursue them are set. They are usually people looking to get involved in many activities. However, their performance does not allow them to meet it successfully. By contrast, the $48.57 \%$ of people speaking more realistic and attainable goals arise.

Regarding intellectual, identified by $\mathrm{DQ}+$, the results showed that $28.57 \%$ of the population has a high intellectual potential, as they have real processes of analysis, synthesis, and creativity, unlike the rest of the population which constitutes the $71.43 \%$ thereof having difficulty in establishing such processes. This feature is related to the results of the measurement scale existence of intellectual limitation CVD, in which it was found that $2.85 \%$ have some limitation. Excluding the $97.14 \%$ of the population who did not have a significant score on this scale.

The results obtained by COP in social categorization shown in Figure 6, claim that $91.42 \%$ of the sample has little interest in interpersonal relationships, and shows only $8.57 \%$ are people who display attitudes of collaboration. However, although the percentage tends to disregard for the people, this does not mean that tend to fall into isolation. Furthermore, because a significant score in GHR was not obtained: PHR for interpretation, 
ruling out the existence of maladaptive behaviors in interpersonal relationships of the subjects of the study population. As for the type of role they assume in relationships identified by a: p, the $94.29 \%$ of the population showed that their role is poorly defined. Meanwhile, the $2.86 \%$ is flat, and $2.86 \%$ is active.

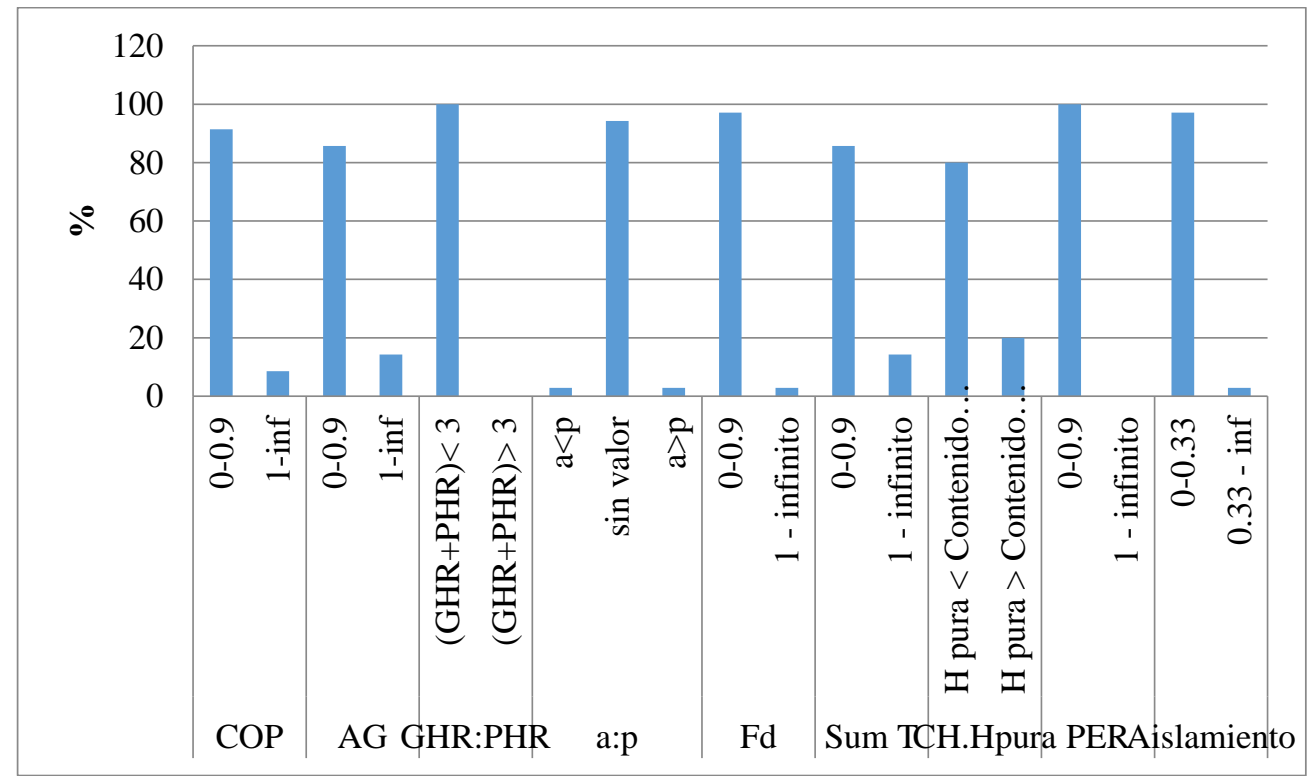

Figure 6. Interpersonal

Moreover, the determining Fd identifies that only 2.85\% of the sample, are persons with dependent features, $97.14 \%$ had no significant score in that decisive. This feature is according and the findings of the scale of need for closeness with sumT another person, for the $14.28 \%$ of the population, revealed the need to be led by paternalistic behavior. The $85.71 \%$ is within the expected average on the scale.

As for the human contents, he found that only $20 \%$ of the sample is interested in other people, unlike the $80 \%$ who do not show any interest. Finally, the PER scale identifies the degree of defensiveness; I, no score was obtained so that their interpretation could not be applied to this sample. Finally, Figure 7 shows the results achieved regarding the categorization of perception. According to the final 3rd + (2) / R, it can be concluded that only $62.85 \%$ of the sample sees itself as responsible and center of their problems, leaving $37.13 \%$ off with the likelihood that not take responsibility. Fr also identifies the $97.14 \%$ of the population have enough resources when it comes to function in environments where they are consistently recognized, and who like to be admired. 


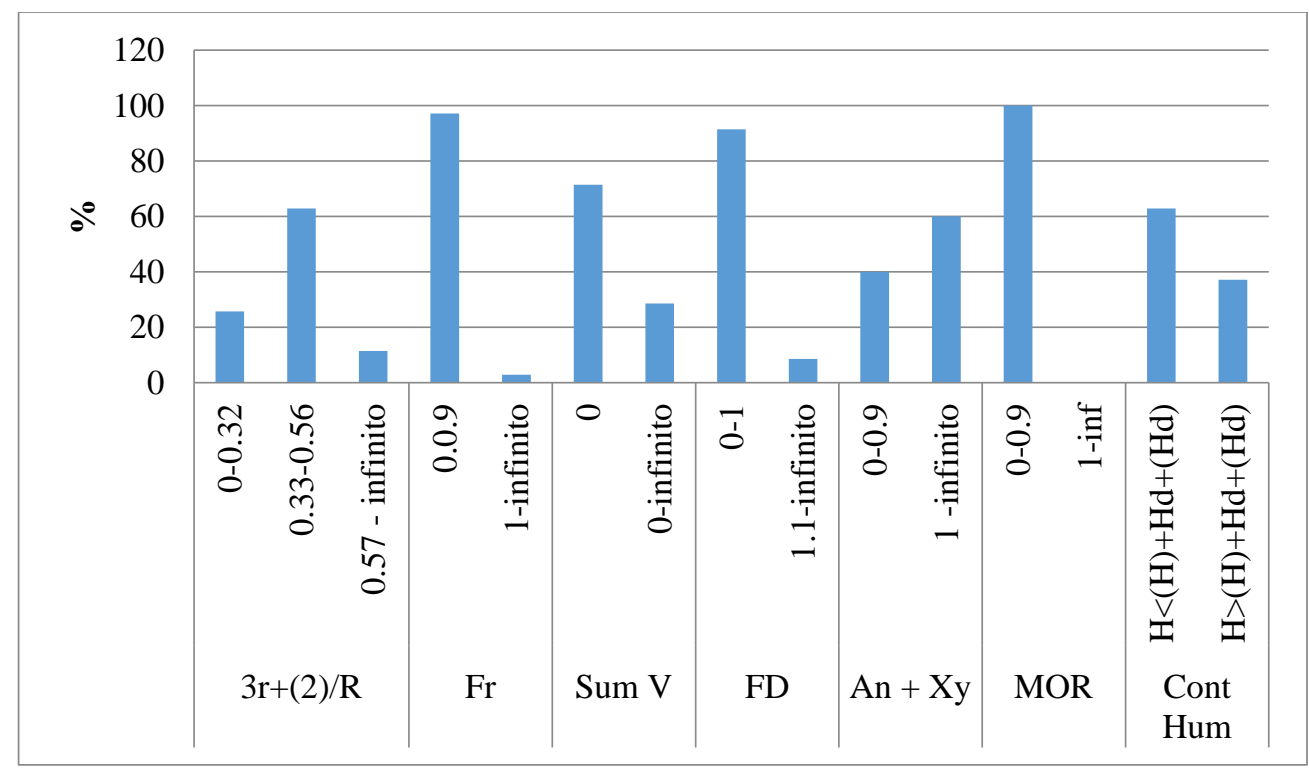

Figure 7. Self-perception

According to the sum, it is identified that only $71.42 \%$ of the sample has good self-confidence since $28.57 \%$ are people who become very hard to themselves, which comes to affect their self-concept. This assertion confirmed by the results of FD.

Moreover, the results of the determinant An + Ay, show that $60 \%$ of the population is at risk for problems on the self-image, self-concept issues related to the property. Only $40 \%$ are exempt from such chance. However, MOR results confirm that although such a feature, $100 \%$ of the sample are less depressed people. Overall, the results provided by the determining $\mathrm{H}$ : $(\mathrm{H})+\mathrm{Hd}+(\mathrm{Hd})$ speaks of the existence of an unrealistic perception of selfimage in $62.85 \%$ of the population. Dismissing such property only to $37.14 \%$.

\section{Conclusion}

The analysis of the results obtained by applying the ZT organizational psychologists in training, allowed identify those personality traits that are shown as prevailing and, therefore, make a profile.

It was found that $100 \%$ of students made up the sample were unaware of the existence of ZT.

According to the organization of the results based on ZT. Traits are identified, considered strongholds for the professional performance of the students. Some of them are the use of sound judgment and discretion, adaptability to routine and facility to develop creative aspects, attention to detail, perceptual context adequacy active and autonomous role. 
Traits considered as areas of opportunity identified. Impulsiveness, poor control of emotions, lack of empathy and concern for others, the development of resources and effective coping strategies. It takes work to develop a real, healthy and objective to strengthen his personality self-image.

Identification of the main features of the personality of students in training allowed for a first approach to know what those features that characterize the psychologists in training at a private university are. This identification gave that patient cannot make a generalization, however, it can open other fields of study to expand the assessment as to the profiles of students.

The possibility of conducting studies with the ZT in the selection of personnel in various fields was also raised.

\section{References:}

Ceballos, L. y Solis, S. (2004). Propuesta de Parámetros Referenciales para la Utilización del Test de Zülliger Individual en Selección de Personal. (Tesis de Licenciatura, Universidad de Chile). Recuperado de: http://www.tesis.uchile.cl/handle/2250/106395

Gallardo, R. I., Álvarez, A. Y. y Rojas, G. M. Estudio de la Validez Predictiva del Examen Especial de Admisión de Alumnos a la Carrera de Psicología. Revista de Psicología de la Universidad de Chile, Vol. XII, No. 1: pp. 65-81. 2003.

González, F.M. (2007). Instrumentos de Evaluación Psicológica. La Habana: Editorial Ciencias Médicas.

Hernández-Sampieri, R., Fernández, C. y Baptista, M. (2014). Metodología de la Investigación. México: McGrawHill

Moritán, J. I. (2006). Análisis de la Tríada Cognitiva del Sistema Comprehensivo Exner en Protocolos de sujetos evaluados con el Test de Zulliger en situación de Selección de Personal. XIII Jornadas de Investigación Y Segundo Encuentro de Investigadores en Psicología del Mercosur. Facultad de Psicología. Universidad de Buenos Aires, Buenos Aires.

Núñez, A. M., Guzmán, L., Gurtner, G., Sobrero, M., Díaz, K.I y Lara, G. M. (2011). Tipo Aperceptivo en el Z Test Individual, en una muestra Argentina. III Congreso Internacional de Investigación y Práctica Profesional en Psicología XVIII Jornadas de Investigación Séptimo Encuentro de Investigadores en Psicología del MERCOSUR. Facultad de Psicología. Universidad de Buenos Aires, Buenos Aires.

Núñez, A. M., Lara, G, Guzmán, L., Gurtnr, G. y Díaz, K. I. (2010). Test de Zulliger: Datos Normativos de Determinantes en una Muestra de Jóvenes entre 20 y 30 años, Residentes en la Ciudad Autónoma de Buenos Aires y sus alrededores. Facultad de Psicología UBA Anuario de Investigaciones. Vol. 
XVII. Pp. 179-184.

Rivera, C. S. Estandarización del Procedimiento de Administración del Yest de Zulliger. Comunicación Libre 23. Universidad de Lima.

Redondo, A.I., Oggero, H. A. y Moritán, J.I. (2005). Determinación de estadísticos descriptivos de la agrupación Controles en Respuestas al Test de Zulliger en personas de 31-40 años en situación de selección de personal. XX Jornadas de Investigación y Primer Encuentro de Investigadores en Psicología del Mercosur. Facultad de Psicología. Universidad de Buenos Aires.

Richino, S.V. (1996). Selección de Personal. Buenos Aires: Editorial Paidós. Zdunic, A., Agemian, C., Kimmelman, P. y Magazzu, M.R. (2011) Zulliger500. Actualizando datos normativos. Poster presentado en las XVIII jornadas de Investigación y Sexto Encuentro de Investigadores en Psicología del MERCOSUR, Bs.As. Noviembre 2011. 